\title{
Industrial and Environmental Safety and Efficiency of Gas Transportation Industry
}

\author{
Bogdan U. Vasiliev ${ }^{1 *}$ and Dmitrij V. Mardashov² \\ 'Department of Electric Energy and Electromechanical, Saint-Petersburg Mining University, Russian Federation, \\ Saint Petersburg, 21 lines, Russia, 199106; va-silev.bu@spmi.ru \\ 2Department of Oil and Gas Fields Development, Saint-Petersburg Mining Universi-ty, Russian Federation, \\ Saint Petersburg, 21 lines, Russia, 199106; dmit-ry_mardashov@mail.ru
}

\begin{abstract}
Objectives: Analysis of the influence of the drive type of gas compressor units on industrial safety and ecological efficiency of the main gas pipelines. Methods/Statistical analysis: Analysis of the main drive types of gas compressor units was carried out. Analysis of the main factors, which influence on industrial safety and ecological efficiency of the main gas pipelines, was carried out. It is shown, what technologies in a driver of gas compressor units are used to improve industrial safety and ecological efficiency of the main gas pipelines. Findings: The main drive types of gas compressor units are: gas turbines; electric drives; gas engine compressors. The main factors that influence industrial safety and ecological efficiency of the main gas pipelines, when using gas turbine gas compressor units are: emissions of harmful substances in the atmosphere; toxic waste; noise and vibration. When using gas turbine gas compressor units there is an additional problem of energy saving on the main gas pipelines. The best way to improve industrial safety and ecological efficiency of the main gas pipelines is to use electrically driven gas compressor units. The most effective and well-proven are electrically driven gas compressor units, built on the concepts of HOFIM and MOPICO. Application/Improvements: The results of work can be used in the analysis and development of methods to improve industrial safety and ecological efficiency of the main gas pipelines.
\end{abstract}

Keywords: Electric Gas-compressor Units, Energy Efficiency, Environmental Safety, Gas Transportation System, Industrial Safety

\section{Introduction}

The gas industry plays a strategic role in economy of Europe. About a half of total production and internal consumption of energy resources depends on natural gas. With refusal of coal the role of natural gas will only continue to grow in an energy balance.

The most powerful Gas Transportation System (GTS) functions for transportation of natural gas from places of its production to consumers in Europe. Main suppliers of natural gas are Norway, Great Britain, France, the
United Arab Emirates and Russia. The main consumers of the Russian natural gas in Europe are Germany and Italy. The Figure 1 shows the scheme of the gas transportation system of Europe.

The stable development of the European countries depends on a reliable and efficient function of the gas transportation system $\frac{1,2}{2}$. With high reliability of GTS it is necessary to ensure its industrial and environmental safety. In this article the major factors influencing on an industrial and ecological safety of GTS are analyzed,

${ }^{*}$ Author for correspondence 


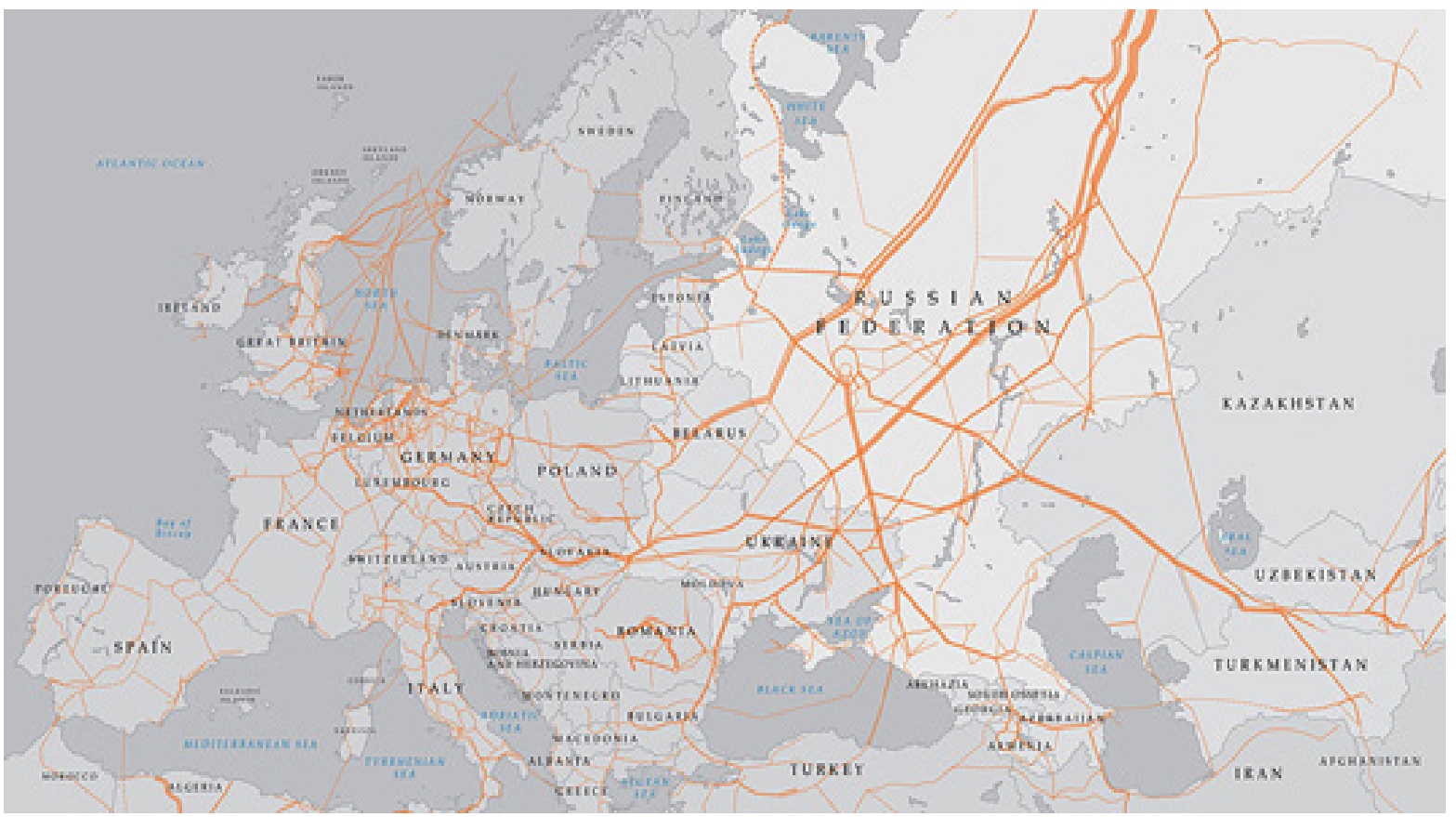

Figure 1. Scheme of the gas transportation system in Europe.

sources of GTS safety decreasing are revealed, measures for providing safety are proposed.

\section{Materials and Methods}

\subsection{Structure of Park of Gas-compressor Units}

The main elements of Gas-Transportation Systems (GTS) are Main Gas Pipelines (MGP) and Compressor Stations (CS), which consist of compressor shops. The compressor shop consists of Gas-Compressor Unit (GCU), gas coolers, power supply system, water supply system, alarm system, fire extinguishing and room artificial climate system, connection points, shutdown safety valves, stop valves, dust collectors etc. The gas-compressor units are the largest consumers of energy resources and, in fact, are a power center of the gas transportation system.

The working body of the gas-compressing units is Centrifugal Superchargers (CS) which compress and transport the natural gas along a main gas pipeline. Power of centrifugal superchargers, now in use on the main gas pipelines, varies from 2.5 to $32 \mathrm{MW}^{2}$. The following engine types are used for driving the centrifugal superchargers:

- gas turbine engines

- electric motors

- gas engine compressors

Figure 2 (a) shows the external view of the RollsRoyce (Great Britain) gas-compressor unit driven by a gas turbine, Figure 2 (b) is the Siemens (Germany) electric gas-compressor unit, Figure 2 (c) is the Caterpillar (USA) gas-compressor unit driven by a gas engine.

More than half of park of gas-compressor units in Europe have the gas turbine drive. For gas turbine gascompressor units a natural gas is used as a main fuel, which is transported in main gas pipelines. Combustion of natural gas in a huge number at compressor stations leads to decrease in level of an industrial and ecological safety. 


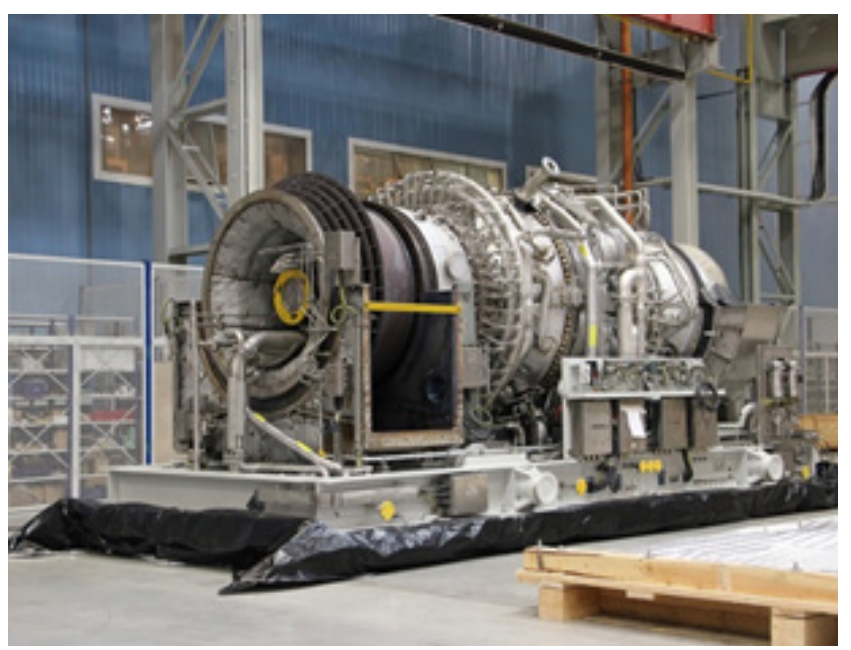

(a)

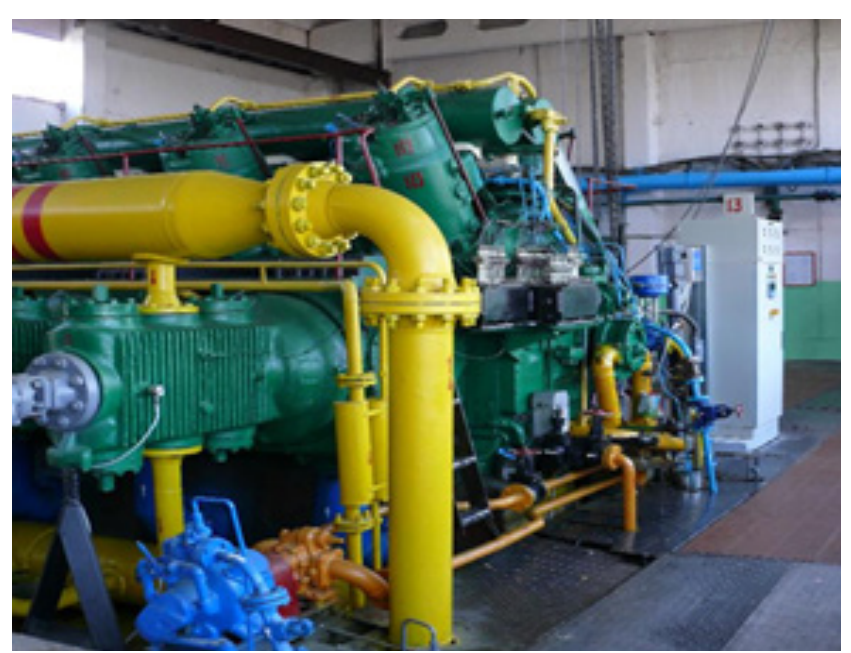

(b)

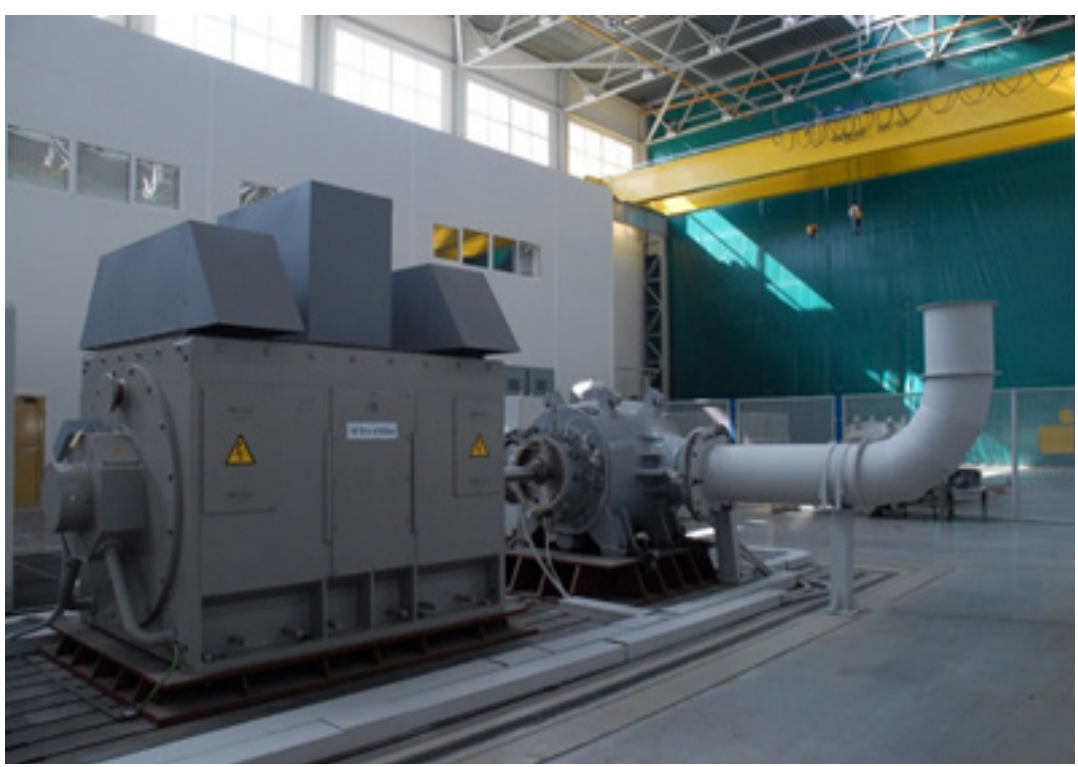

(c)

Figure 2. Different types of gas-compressing units.

\subsection{Industrial and Environmental Safety of Gas-transportation System}

Level of an industrial and ecological safety of gas transportation system objects is in a direct connection with reliability of the system. Many of the measures directed to increase of gas transportation system reliability should be considered as a way of decrease in risks of defeat and death of people and environment violation, i.e. safety increase.

Efficiency and safety of the gas transportation system functioning is substantially determined by ecological compatibility of work of the system main objects, one of which is a compressor station. Exactly here the greatest number of the power-intensive equipment intended for ensuring technological process of natural gas transporta- 
tion is concentrated, branched systems of technological communications function and a large number of service personnel are involved $\frac{3-5}{}$.

The main sources of the polluting substances are the gas-compressor units driven by gas turbines, centrifugal superchargers, oil degasser and technological processes connected with their operation.

\subsection{Main Factors of Gas-compressor Unit Impact on Environment}

Let's observe the main factors of the gas-compressor unit impact on environment:

- emissions of harmful substances in the atmosphere
- toxic waste

- noise and vibration

- Thermal influence

\subsubsection{Emissions of Harmful Substances in the Atmosphere}

These are emissions of natural gas and emissions of combustion products (exhaust gases of the gas-turbine engine). Table 1 shows parameters of technical standards of emissions of gas-compressor unit polluting substances, received experimentally.

Emission of natural gas on compressor station happens at start-up and stop of the gas-compressor unit, and

Table 1. Emissions of polluting substances of gas-compressor units

\begin{tabular}{|c|c|c|c|c|c|}
\hline Parameter & \multicolumn{5}{|c|}{ Parameter values } \\
\hline $\begin{array}{l}\text { Power of gas-compressor unit } \\
{[\mathrm{MW}]}\end{array}$ & $2 \div 4$ & $6 \div 8$ & $10 \div 13$ & $16 \div 18$ & $22 \div 31$ \\
\hline Fuel gas consumption $[\mathrm{m} 3 / \mathrm{h}]$ & $1106 \div 1795$ & $1824 \div 2872$ & $3077 \div 5051$ & $4720 \div 6593$ & $6889 \div 10539$ \\
\hline $\begin{array}{c}\text { Temperature of combustion } \\
\text { products }\left[{ }^{\circ} \mathrm{K}\right]\end{array}$ & $1113 \div 1270$ & $947 \div 1295$ & $1053 \div 1456$ & $1130 \div 1456$ & $1188 \div 1518$ \\
\hline \multicolumn{6}{|c|}{ Concentration in dry combustion products: } \\
\hline nitrogen oxide $[\mathrm{mg} / \mathrm{m} 3]$ & $35 \div 136$ & $69 \div 202$ & $69 \div 199$ & $48 \div 179$ & $50 \div 353$ \\
\hline carbonic oxide $[\mathrm{mg} / \mathrm{m} 3]$ & $25 \div 82$ & $33 \div 239$ & $29 \div 275$ & $48 \div 229$ & $41 \div 441$ \\
\hline \multicolumn{6}{|c|}{ Modified concentration: } \\
\hline nitrogen oxide $[\mathrm{mg} / \mathrm{m} 3]$ & $50 \div 195$ & $135 \div 490$ & $100 \div 230$ & $80 \div 250$ & $50 \div 400$ \\
\hline carbonic oxide $[\mathrm{mg} / \mathrm{m} 3]$ & $30 \div 130$ & $90 \div 300$ & $60 \div 300$ & $80 \div 300$ & $50 \div 500$ \\
\hline
\end{tabular}


Table 1 Continued

\begin{tabular}{|c|c|c|c|c|c|}
\hline \multicolumn{6}{|c|}{ Emission efficiency: } \\
\hline nitrogen oxide $[\mathrm{g} / \mathrm{s}]$ & $0,52 \div 1,67$ & $2,58 \div 6,93$ & $2,38 \div 7,81$ & $3,29 \div 11,8$ & $2,91 \div 26,65$ \\
\hline carbonic oxide $[\mathrm{g} / \mathrm{s}]$ & $0,41 \div 1,35$ & $1,5 \div 6,66$ & $1,81 \div 8$ & $3,5 \div 14,5$ & $3,59 \div 39,08$ \\
\hline \multicolumn{6}{|c|}{ Specific emission on fuel gas unit: } \\
\hline nitrogen oxide $[\mathrm{g} / \mathrm{s}]$ & $1,39 \div 5,42$ & $3,75 \div 13,62$ & $2,78 \div 6,39$ & $2,22 \div 6,95$ & $1,39 \div 11,12$ \\
\hline carbonic oxide $[\mathrm{g} / \mathrm{s}]$ & $0,83 \div 3,61$ & $2,5 \div 8,75$ & $1,67 \div 8,34$ & $2,22 \div 8,34$ & $1,39 \div 13,9$ \\
\hline \multicolumn{6}{|c|}{ Specific emission on thermal power unit: } \\
\hline nitrogen oxide $[\mathrm{g} / \mathrm{GJ}]$ & $41 \div 162$ & $112 \div 407$ & $83 \div 249$ & $66 \div 207$ & $41 \div 332$ \\
\hline carbonic oxide $[\mathrm{g} / \mathrm{GJ}]$ & $24 \div 108$ & $75 \div 249$ & $49 \div 174$ & $66 \div 249$ & $41 \div 415$ \\
\hline \multicolumn{6}{|c|}{ Specific emission on unit of work: } \\
\hline nitrogen oxide [g/kWh] & $0.47 \div 2.31$ & $1.48 \div 5.88$ & $0.86 \div 2.16$ & $0.73 \div 2.59$ & $0.43 \div 3.92$ \\
\hline carbonic oxide $[\mathrm{g} / \mathrm{kWh}]$ & $0.29 \div 1.22$ & $0.9 \div 3.73$ & $0.65 \div 2.73$ & $0.8 \div 3.27$ & $0.54 \div 5.12$ \\
\hline \multicolumn{6}{|c|}{ Specific emission on gas supply unit: } \\
\hline $\begin{array}{l}\text { nitrogen oxide }[\mathrm{g} / \text { thousands of } \\
\left.\qquad \mathrm{m}^{3}\right]\end{array}$ & $6 \div 114$ & $11 \div 24$ & $10 \div 37$ & $8 \div 18$ & $5.28 \div 48.99$ \\
\hline $\begin{array}{l}\text { carbonic oxide }[\mathrm{g} / \text { thousands of } \\
\left.\qquad \mathrm{m}^{3}\right]\end{array}$ & $4.17 \div 49.22$ & $5.40 \div 52.89$ & $4.34 \div 32.50$ & $9.06 \div 37.73$ & $6.53 \div 61.23$ \\
\hline
\end{tabular}

also during operation with tightness violation of its main parts.

The exhaust gases are created as a result of the natural gas combustion in the gas turbine of the gas-compressor unit. They consist of:
- combustion products - nitrogen, water vapor, carbon dioxide;

- nitrogen oxides; 
- carbon dioxide

- sulphur oxides

- hydrocarbons (including not completely burned methane)

- soot.

At combustion of the gases containing hydrogen sulfide, sulfuric and sulphurous anhydrides, not burned hydrogen sulfide are also released into the atmosphere.

The Directive of the European Parliament and Council 2001/80/EU specifies maximum permissible values of emissions in relation to the gas-turbine engines of gas-compressor units certified before 11/27/2002 and accepted for operation before 11/27/2003:

- on nitrogen oxides of $50 \mathrm{mg} / \mathrm{m} 3$ when using as fuel natural gas with the content of inert gases no more than $20 \%$

- on nitrogen oxides of $75 \mathrm{mg} / \mathrm{m} 3$ for gas-turbine engines in cogeneration installations with the general efficiency more than $75 \%$, for gas turbines in a combined heat and power plant (CHP plant) with the general average annual efficiency more than $55 \%$.

\subsubsection{Toxic Waste}

Gas-compressor unit has lubricating systems of the gas turbine engine and the centrifugal supercharger. hydraulic systems of the centrifugal supercharger shaft sealing which use different lubricating oil types with storage oil tanks for the engine and the centrifugal supercharger accordingly ${ }^{6}$.

During work of the gas-compressor unit toxic substances are emitted from oil tanks of the gas-turbine engine and the centrifugal supercharger, from the oil degasser of the supercharger sealing system.

The toxic substances arriving from a shaft oil sealing system of the centrifugal supercharger because of pressure difference in the supercharger and the degasser, which is under atmospheric pressure, are emitted in the degasser. Toxic substances are emitted in atmospheric air from oil tanks of the gas-turbine engine and a centrifugal supercharger in which the oil heated in the engine and the supercharger circulates.

For gas-compressor units with power up to $10 \mathrm{MW}$ inclusive, irrevocable losses of oil should not exceed: with stationary gas-turbine installations - $1.0 \mathrm{~kg} / \mathrm{h}$; with converted engines $-2.0 \mathrm{~kg} / \mathrm{h}$; for gas-compressor units with power more than $10 \mathrm{MW}$ : with stationary gas-turbine installations $-1.5 \mathrm{~kg} / \mathrm{h}$; with converted engines $-2.5 \mathrm{~kg} / \mathrm{h}$.

\subsubsection{Noise and Other Types of Influence}

Noise pollution of the atmosphere is an operation consequence of gas-compressor units and traffic (road transport. helicopters. etc.). If noise levels exceed health protection standards. Serious problems for service personnel arise.

Gas-compressor units have four main (primary) sources of noise: gas-turbine engine; compressor; centrifugal supercharger; fans. The main sources of noise are paths of suction and exhaust of gas turbine installations.

Let's examine basic reasons of a low effectiveness of the existing silencers of noise suppression systems: pattern incompatibility of absorption and emission spectrum; existence of acoustic bridges (bypassing the silencer) for a sound distribution; insufficiency of a sound-absorbing surface area; defects of a design (assembly gaps. unreasonably large cross sections); short life of the used sound-absorbing material (foam rubber).

The noise suppression of the gas-compressor unit is carried out by four main methods. Let's examine these methods:

- dissipative noise suppression in paths of suction and exhaust. For noise reduction by this methods absorbers of resonant type are used of which elementary method is the limited air cavity connected by an opening (throat) to environment. 
- use of jet silencers (resonators). The principle of operation of these silencers is «locking» of extending modes of sound vibrations and their reflection on the channel back to a noise source.

- active noise suppression in channels. The physical mechanism of noise reduction when using active methods consists, as well as in case of use of the usual soundproofing systems, in addition of fluctuations with various phases, at the same time however the secondary (compensating) field is created not in the passive way (for example by reflection), but is radiated by special electroacoustic converters.

- combination. Entering of absorption elements of sound energy in jet silencers improves their parameters since sound reflection effect from jet type devices is weakened, and also levels of sound pressure in forming zones of not extending modes of fluctuations are decreased. Sound-absorbing elements provide dissipative withdrawal (drain) of acoustic energy, transferring it to thermal energy. When a sound dissipation in natural absorbers is small, the absorbing elements are introduced into the jet silencers.

\subsubsection{Thermal Influence}

Use gas-turbine engines in the gas-compressor unit drive leads also to thermal impact on environment and emergence of geo-ecological factors. Thermal influence of compressor station on environment is especially actually during the operation in the conditions of permafrost.

\subsubsection{Energy Saving Problem}

The gas consumption on own needs which first of all fall on fuel gas for gas-turbine engines of gas-compressor units can constitute up to $5 \%$ of transportation amount for $1000 \mathrm{~km}$ of the route. Therefore in absolute value in case of transportation distance more than $5000 \mathrm{~km}$ the gas consumption on own needs of compressor station will be very considerable. The solution of this problem has several main aspects:

- decrease in energy consumption for a gas compression due to use of gas-compressor unit with the efficiency high values of the gas-turbine engine and the centrifugal supercharger

- decrease in pressure lost during gas transportation in a gas pipeline due to: use of pipes with an internal smooth covering; periodic cleaning of the pipeline internal space; use of high-performance equipment and gas piping of compressor station

- decrease in the general energy consumption due to application of energy saving technology.

During development of gas transportation technology, the gas energy saving is the same factor, as other important resource-saving factors connected with investments, metal investments and operating costs.

The choice of gas transmission technology first of all depends on a ratio between the cost of pipes and the equipment of compressor station on the one hand and the gas consumed for own needs, on the other hand. The final decision shall be made by means of optimization of the economic indicators characterizing efficiency of the project and the ecological safety of the project.

\section{Results and Discussion}

\subsection{Electric Gas-compressor Units (EGCU)}

Use of the electric gas-compressor units radically ensures an industrial and ecological safety. Their use provides:

- exclusion of natural gas use as a fuel for the drive of the gas-compressor unit

- exclusion of emissions of natural gas combustion products in the atmosphere

- exclusion of necessity has a toxic oil treatment device 
- absence of compressor station thermal impact on environment

- absence of noise and vibration pollution

- high level of resource-saving for compressor station

- increased level of compressor station reliability
- possibility to create unmanned technologies of natural gas transportation.

\subsection{Experience of Use of Electric Gas- compressor Units}

The world electric companies, such as ABB. MAN. Siemens, etc. are leaders in research, development and production of electric gas-compressor stations ${ }^{7}$.

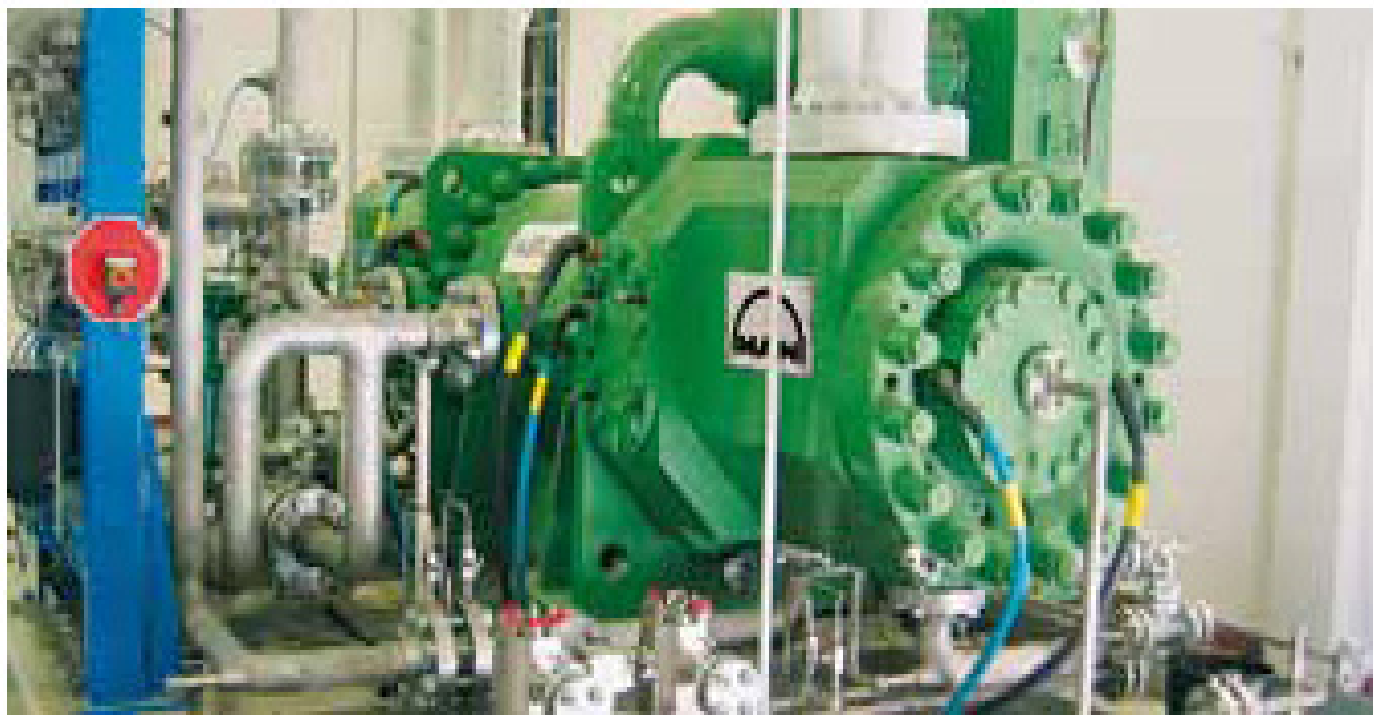

(a)

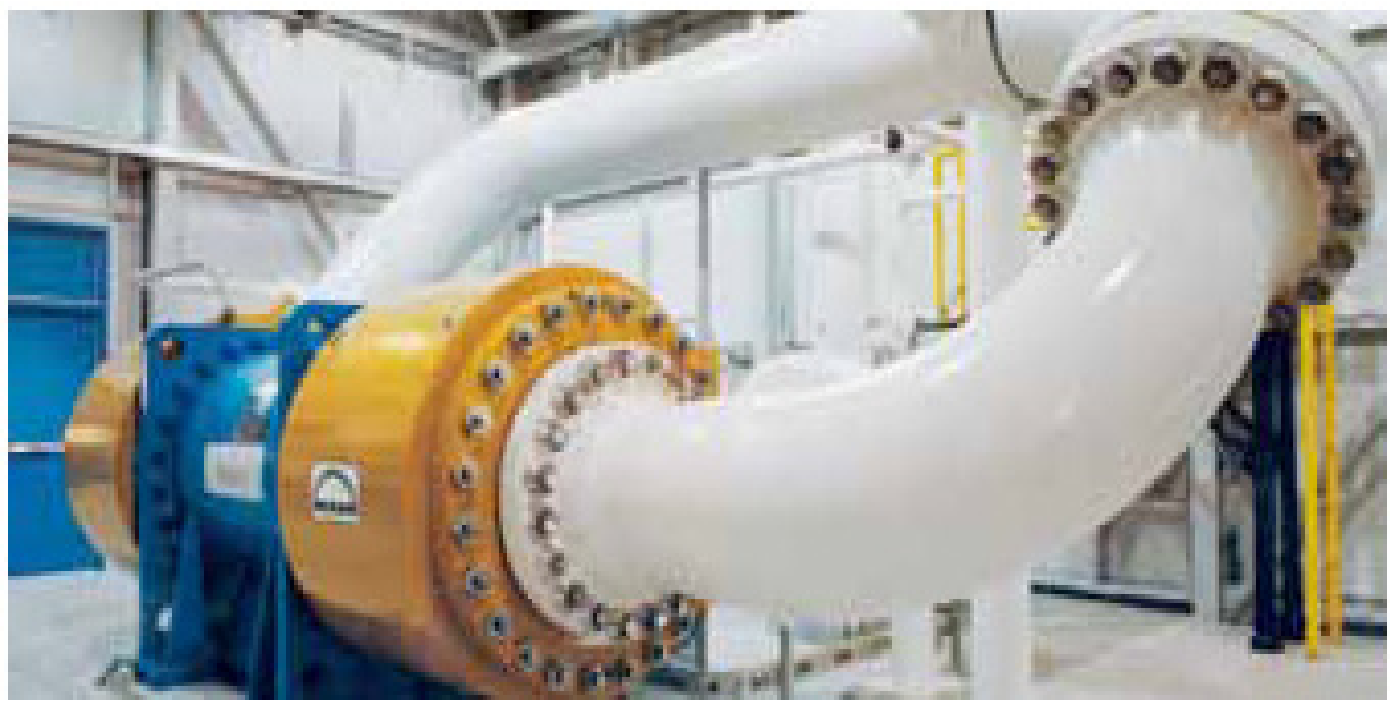

(b)

Figure 3. Electric gas-compressor units made according to the technologies HOFIM and MOPICO. 
Electric gas-compressor stations were widely adopted in Europe. America and the countries of the AsiaPacific Region?․․ Let's review some examples of use of electric gas-compressor stations in the different countries.

The German gas transmission company Thyssengas, is one of regional operators of main pipelines in Germany? At compressor station Hünxe which is located in the federal land Northern Rhine-Westphalia gas-compressor units of 6.3 MW driven by a gas-turbine were used since 1991. In 2000 these gas-compressor units have been replaced with electric gas-compressor units for ensuring environmental friendliness and energy efficiency. The ALSTOM company installed on Hünxe compressor station the $6 \mathrm{MW}$ adjustable electric motor drive of an alternating current and rotating speed 12700 RPM, made according to the HOFIM technology - high speed-oil free compression system (Figure 3 (a)). Also, due to use of electric gas-compressor unit the compressor station Hünxe has been completely automated, including dimensions of compressor station were reduced and emissions of greenhouse gases and leak of oil from lubricating oil systems were excluded.

Experience of the American gas transmission company Columbia Gas Transmission Corp can serve as other example of use of electric gas-compressor unit of the ALSTOM company at compressor station Rutledge. Originally, the Rutledge station has been developed for use of gas piston engines. However, the proximity of residential communities, noise and a large number of emissions of greenhouse gases from the working gas-compressor unit was not compatible. These circumstances have forced the company to modernize Rutledge compressor station and to replace gas-piston engines with electric gas-compressor unit. In this case the ALSTOM company used electrical gas-compressor unit made according to the MOPICO technology - motor pipeline compressor (Figure 3 (b)). This unit represents the hermetic compressor driven by an asynchronous engine. The electric motor which is installed in the unit rotates two centrifugal superchargers. Power of these unites is $3 \mathrm{MW}$, rotating speed is $10000 \mathrm{RPM}$.

\subsection{Technologies of Electric Gas- compressor Units}

The HOFIM and MOPICO technologies are the main in the world according to which the leading electric companies produce electric gas-compressor units $\frac{10,11}{1}$. The main features of these units are the arrangement of the high-speed electric motor and compressors in the tight single case, and they are installed on common shaft which is supported by magnetic bearings. Thus, the drive and operating device are connected without gears and couplings.

\section{Conclusions}

The type of the gas-compressor unit drive shall be chosen based on the system and detailed analysis of technical and economical and other factors in case of construction and reconstruction new and old compressor stations respectively. The reliable and regular natural gas supply of consumers and ensuring development of economy of Europe shall be a main goal of construction and reconstruction of compressor stations.

Underwater electric gas-compressor units of special designs are non-competitive technical means for a natural gas compression on a seabed at development of offshore fields. In this case the highest requirements should be imposed to the electric drive and whole unit concerning reliability of its functioning and providing a continuity of all technological processes of natural gas transportation.

\section{References}

1. Zyrin VO, Vasiliev BU. Electrothermal complex with dowhole elec-trical heating generators for enhanced heavy oil recovery. International Journal of Applied Engineering Research. 2016; 11(3):1859-66.

2. Mardashov DV, Vasiliev BU. Development of well killing technology during well service on oil gas and condensate fields with carbonate reservoirs. International Journal of Applied Engineering Research. 2015; 10(22):43103-5.

3. Cortinovisa A, Ferreaua H.J, Lewandowskib D, Mercangöza M. Ex-perimental evaluation of MPC-based anti-surge and process control for elec-tric driven centrifugal gas compressors. Journal of Process Control. 2015; 34:13-25. 
4. Verma M, Parker D, Grinbaum II, Nanney J. Converting to electric motors and adjustable speed drives: A case study of a 20.000HP gas turbine driven compressor. IEEE Petroleum and Chemical Industry Committee Conference, USA; 2015. p. 1-9.

5. Wil B, Mol V. Direct electric drives for the west-east pipeline - flexible, efficient and with a high degree of availability. Petro Min PipeLiner. 2010; 2(08):24-7.

6. Wyszkowski M, Sivitskaya V. Effect of different substances on some properties of soil contam-inated with heating oil. Journal of Ecological Engineering. 2015; 16(1):62-6.

7. Kozyaruk AE, Vasilev BY. Structure. composition. and control algorithms of high-efficiency electric drives of gas- compressor units. Russian Electrical Engineering. 2013; 84(2):94-102.

8. Higashi N. Natural gas in china. Market evolution and strategy. Energy markets and security: Beijing; 2009. p. 1-39.

9. Behmer P, Meyer B. Verdichterstation ochtrup mit elektroantrieb und regelbarem planeten-getriebe. GWF Gas Energie. 2011; 152(7-8):462-5.

10. MAN. HOFIM technology oil-free compression systems. MAN Press: Zurich; 2012. p. 1-6.

11. MAN. MOPICO Compact compression system for gas transport. MAN Press: Zurich; 2014. p. 1-6 